\title{
QTL MAPPING FOR SALT TOLERANCE AT REPRODUCTIVE STAGE IN RICE: A MINIREVIEW
}

\author{
Nguyen Sao MAI and Yoshihiko HIRAI* \\ Graduate School of Environmental and Life Science, Okayama University \\ (1-1-1 Tsushima-naka, Kita-ku, Okayama 700-8530, Japan) \\ *E-mail: yhirai@okayama-u.ac.jp
}

\begin{abstract}
Salt stress is one of the major abiotic stresses limiting rice production worldwide. Since the expansion of saline soil continues, there is a need to develop salt-tolerant rice varieties with high yields to ensure food security. Detecting quantitative trait loci (QTLs) for salt tolerance contributes greatly to breeding; however, limited studies have reported on the reproductive stage due to time-consuming and laborious processes. This review on QTL mapping for salt tolerance at the reproductive stage in rice shows that almost all QTLs explain small phenotypic variations scattered over the genome. Still, several QTLs were mapped in the same region on chromosomes 1, 2, and 6. The pyramiding of such QTLs is expected to improve tolerance and yield in elite varieties.
\end{abstract}

Key Words: QTL analysis, salinity tolerance, reproductive stage, yield, rice

\section{INTRODUCTION}

By the mid-twenty-first century, rice and other cereal production must reach 3 billion tons to meet the demand of the world's growing population [1]. However, salt stress, a major hindrance to rice production, seems to continue due to natural events and mismanaged agricultural practices. According to Food and Agriculture Organization of the United Nations (FAO), $20 \%$ of total irrigated land was affected by salt stress and resulted in the loss of US $\$ 12$ billion worldwide. Besides, salinization eliminates $1-2 \%$ of irrigated land each year [2]. Breeding of salt-tolerant rice varieties with improved yields is often proposed as a promising economic and energy-efficient solution for this issue [3]. As salt tolerance is controlled by QTLs, the detection of these QTLs and closely linked markers is of great importance for breeding. Though considerable effort has been made, the progress in breeding salt-tolerant varieties in rice has been limited [4].
Rice is sensitive to salt stress and its yield can be affected at an electrical conductivity (EC) as low as 3 $\mathrm{dS} / \mathrm{m}$, while only soil with an EC of $4 \mathrm{dS} / \mathrm{m}$ is considered saline soil [5]. Among growth stages, germination, tillering, and maturity are found to be relatively tolerant to salt stress, while the seedling and reproductive stages are particularly sensitive [6]. Therefore, many studies have been conducted to search for QTLs controlling salt tolerance at these stages; however, many focus on the seedling stage rather than the reproductive stage. The problem is that salt tolerance at the seedling stage does not necessarily correlate with salt tolerance at the reproductive stage [7]. Salt stress at the seedling stage is essential for crop establishment, while grain yield is ultimately determined at reproductive stage [8]. Hence, to produce rice varieties with salt tolerance and high yields, identifying QTLs for tolerance at the reproductive stage is critical. This minireview summarizes QTL mapping results in salt tolerance at the reproductive stage until the present, 
emphasizing important QTLs for grain yield and discussing potential further studies.

\section{EXPLOITATION OF GENETIC VARIATIONS FOR QTL ANALYSIS}

Rice is categorized as sensitive to salt stress though there is considerable variation in salt tolerance levels in different rice varieties, which provides for valuable QTL mapping materials [9]. For example, indica varieties originating from India such as Pokkali, Nona Bokra, Cheriviruppu, and SR26B show tolerance against salt stress. By using biparental populations from crossing those salttolerant donors with sensitive recipient varieties, many QTLs for salt tolerance at the reproductive stage were detected with additive effects from both parents. An $F_{2}$ population was developed from tolerant Cheriviruppu and sensitive Pusa Bastima 1 for QTL analysis. Through a linkage map constructed by $131 \mathrm{SSR}$ markers on $218 \mathrm{~F}_{2}$ individuals, 19 QTLs were detected on chromosomes 1, 2, 3, 4, 7, 8, 10 and 12 [10]. Khan et al. tried to map tolerant QTLs using an $F_{2}$ population derived from IR36 (salt sensitive) and the most popular salt-tolerant donor, Pokkali [11]. One hundred and thirteen $F_{2}$ individuals were genotyped with 111 SSR markers and 6 QTLs were detected on chromosomes 2, 3, 7, and 8. Later, among many Pokkali accessions, AC41585 was detected to be salt tolerant, and by using this accession, 9 QTLs with consistent effects were detected on chromosomes 1, 2, 3, 4, and 11 [12]. Landraces are tolerant to salinity but exhibit poor agronomic traits such as being tall and photosensitive and having poor grain quality and yielding ability [3]. A recombinant inbred line FL478 (derived from Pokkali and IR29) with superior characteristics including photoperiod insensitivity, short stem, and early flowering is often used to overcome this problem. Using an $F_{2}$ population of 232 individuals derived from FL478 and Sadri, 37 QTLs were mapped to chromosomes 1 to 10 [13]. In a $\mathrm{BC}_{2} \mathrm{~F}_{2}$ population derived from a landrace from Vietnam (OM5629) and an elite landrace (OM7347), 4 QTLs were detected on chromosomes 1 and 12 [14]. QTL analysis on an $\mathrm{F}_{2}$ population from a cross between salt-tolerant variety Tarommahalli and Khazar, a susceptible variety originating from Iran, detected 12 QTLs for yieldrelated traits on chromosomes 1, 2, 3, 6, and 7 [15]. Recently, QTL analysis on an $\mathrm{F}_{2}$ population derived from a salt-tolerant variety bred by IRRI (BRRI dhan 47) and a sensitive but high-yielding variety (NSIC Rc222) and genotyped with SNP markers, mapped 7 QTLs to chromosome 1, 2, 5 and 11 [8]. Besides, salttolerant traits were reported to be scattered among different varieties [16], [17]. In terms of utilizing different varieties, QTLs for tolerant traits at the reproductive stage were located in various genomic regions, with only some of them being in common. Hasawi, a salt tolerance landrace from Saudi Arabia, was used as a donor parent to produce $3 \quad F_{2}$ populations with elite recipients (NERICA-L-19, Sahel108, and BG90-2). QTL analysis detected only 24 common QTLs among 75 QTLs for yield and ancillary traits under saline paddy fields in three populations [18]. Two sets of $\mathrm{BC}_{2} \mathrm{~F}_{5}$ introgression lines were developed from two moderately susceptible donors, Budda from India and Gang46B from China and a sensitive recurrent variety Huanghuazhan from China for QTL mapping. Eight QTLs were detected in the Budda/Huanghuazhan population, 7 QTLs in the Gang46B/Huanghuazhan population and they share 3 QTLs in common [19].

\section{QTLs FOR SALT-TOLERANT TRAITS AT THE REPRODUCTIVE STAGE}

Apart from utilizing parental materials for genetic exploitation, phenotypic indicators used for evaluating salt tolerance are another important concern. As rice response varies with salt stress levels and duration, proper screening and phenotyping are recommended for reliable and repeatable results [20]. Salinity exposed at the reproductive stage is known to delay flowering and decrease spikelet fertility, 1000-grain weight, grain yield, and panicle length and number [21]. These yield and yield-related traits are often used for estimating salinity effects on the productive stage. If saltol, a famous QTL for the seedling stage that accounts for more than $40 \%$ 
phenotypic variation, was identified on chromosome 1 [18], QTLs for the reproductive stage were detected with small effects and scattered over the genome (Fig. 1). Four QTLs for grain yield were detected on the short arm of chromosome 2, explaining $7-15 \%$ phenotypic variation [8], [10], [13], [19]. These grain-yielding QTLs colocalized with the same region of QTLs for filled grain number and grain filling. The explanation for the detection of QTLs for different traits in the same genomic region may lie in the presence of a single pleiotropic gene (pleiotropic QTLs) or in the effect of genetic linkage [22]. Two QTLs for grain yield were detected in the same location with a QTL for 1000-grain weight in the short arm of chromosome 6 [13], [18], [19] and another 2 QTLs for grain yield were detected in the same location with QTLs for 1000-grain weight and number of filled grains, branches, and panicles on the long arm [13], [15]. Four QTLs controlling grain yield accounting for $12-15 \%$ of the phenotypic variation were mapped to chromosome 1 in the same regions with QTLs for panicle number, panicle length, biomass, ion concentration and pollen fertility [10], [13]-[15], [18], [19]. As salt-tolerant varieties can maintain a low salt concentration in their tissues, $\mathrm{Na}^{+}$, $\mathrm{K}^{+}$concentration and $\mathrm{Na} / \mathrm{K}$ ratio in leaves and stem were utilized as indicators [23]-[25]. Of these QTLs detected, 2 QTLs for $\mathrm{Na}^{+}$and $\mathrm{Cl}^{-}$concentrations in the leaves explained high phenotypic variation, 26$33 \%$, were mapped adjacent to the position of QTLs for grain yield on the short arm of chromosome 2 [23]. However, Hossain et al. [10] and Pandit et al. [20] showed that the ion concentration in leaves and stem did not correlate significantly with grain yield. Besides, related traits including the days to flowering, pollen viability and total branch, spikelet, and unfilled spikelet number, were used to assess salt effects to provide better insight into underlying salt tolerance mechanisms.

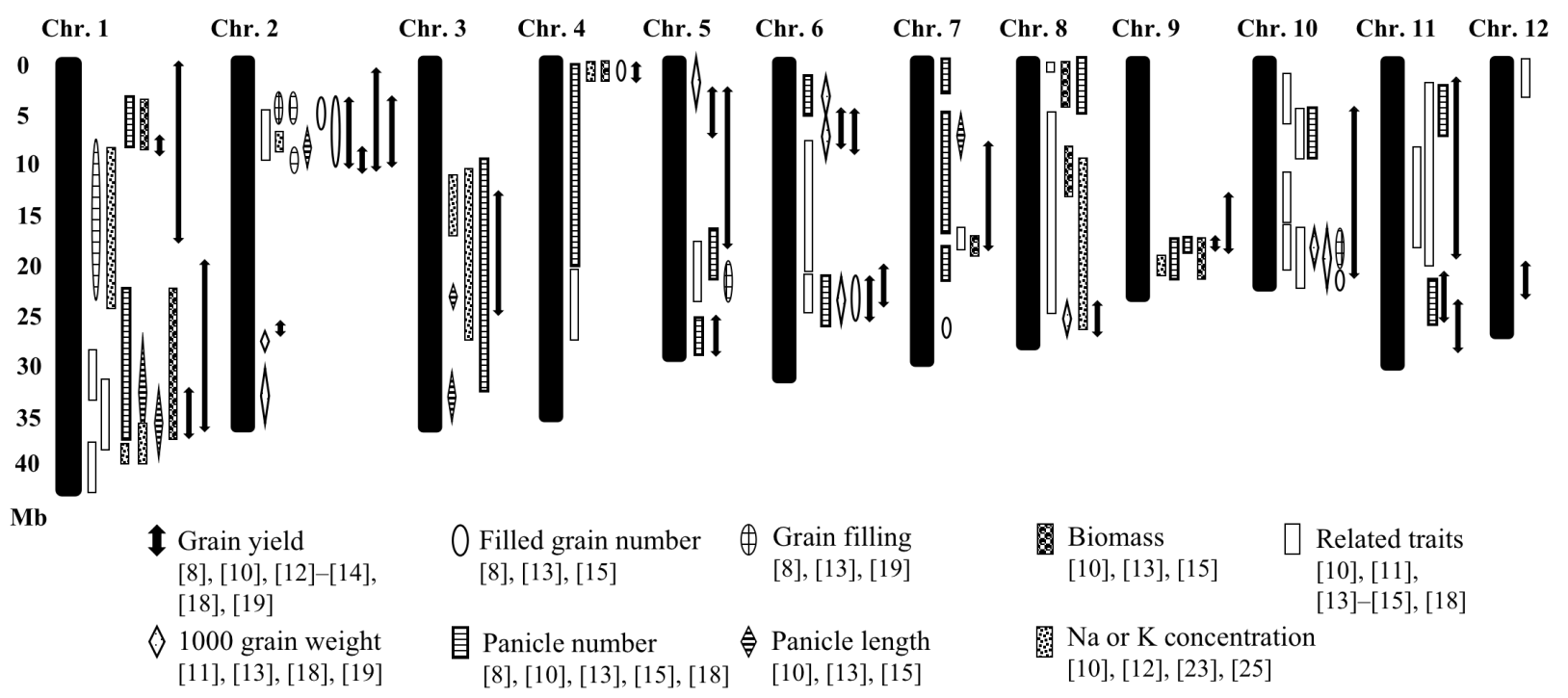

Fig. 1. Locations of QTLs for salt-tolerant traits at the reproductive stage on the rice chromosomes.

\section{CHALLENGES AND SCOPE FOR FUTURE RESEARCH}

Salt-tolerant, moderately-tolerant, and susceptible varieties were used to detect QTLs for various tolerance traits at the reproductive stage. In summary, these studies detected QTLs for reproductive tolerance with low phenotypic variations that were distributed over the genome. This could be the driving reason for none of the detected QTLs having been fine-mapped or cloned. However, several QTLs for yield and yield-related traits that were found to overlap in chromosomes 1 , 2 , and 6 deserve to be further studied to identify causal genes. They could also be important materials for improving salt tolerance at the reproductive stage 33 
rice, the ultimate aim of any breeding program is yield. Since other physiological indicators poorly correlate with grain yield [26], grain yield could be an unequivocal indicator of salt tolerance at the reproductive stage [27]. Using morphological and physical parameters that intimately correlate with grain yield would provide a clearer understanding of maintaining yield mechanisms. In addition to the number of salt-tolerant varieties and wild relatives that are available for future studies, attention should also be paid to sensitive varieties as a hidden source of QTLs for salt tolerance at the reproductive stage.

\section{REFERENCES}

1) Alexandratos, N. and Bruinsma, J.: WORLD AGRICULTURE TOWARDS 2030 / 2050 The 2012 Revision. 2012.

2) FAO: Crops and drops: making the best use of water for agriculture, 2000.

3) Malhotra, R. S. and Blake, T.: Breeding for salt tolerance, Abiotic stress: plant resistance through breeding and molecular approaches, Food Products Press, 2005.

4) Ismail, A. M., Horie, T.: Genomics, physiology, and molecular breeding approaches for improving salt tolerance, Annual Review of Plant Biology, Vol. 68, No. 1, pp. 405-434, 2017.

5) Hoang, T., Tran, T., Nguyen, T., Williams, B., Wurm, P., Bellairs, S. and Mundree, S.: Improvement of salinity stress tolerance in rice: challenges and opportunities. Agronomy, Vol. 6, No. 4, pp. 1-24, 2016.

6) Singh, R. K. and Flowers, T. J.: Physiology and molecular biology of the effects of salinity on rice, 2010.

7) Moradi, F., Ismail, A. M., Gregorio, G. B. and Edane, J. A.: Salinity tolerance of rice during reproductive development and association with tolerance at the seedling stages, Indian Journal of Plant Physiology, Vol. 8, pp. 105-116, 2003.

8) Mondal, S., Borromeo, T. H., Diaz, M. G. Q., Amas, J., Rahman, M. A., Thomson, M. J. and Gregorio, G. B.: Dissecting QTLs for reproductive stage salinity tolerance in rice from BRRI dhan 47, Plant Breeding and Biotechnology, Vol. 7, No. 4, pp. 302-312, 2019.

9) Gregorio, G. B., Senadhira, D., Mendoza, R. D., Manigbas, N. L., Roxas, J. P. and Guerta, C. Q.: Progress in breeding for salinity tolerance and associated abiotic stresses in rice. Field Crops Research, Vol. 76, pp. 91-101, 2002.

10) Hossain, H., Rahman, M. A., Alam, M. S., Singh, R. K.: Mapping of quantitative trait loci associated with reproductive-stage salt tolerance in rice. Journal of Agronomy and Crop Science, Vol. 201, pp. 17-31, 2015.

11) Khan, M. S. K., Saeed, M. and Iqbal, J.: Quantitative trait locus mapping for salt tolerance at maturity stage in indica rice using replicated F2 population, Brazilian Journal of Botany, Vol. 39, No. 2, pp. 641-650, 2016.

12) Chattopadhyay, K., Mohanty, S. K., Vijayan, J., Marndi, B. C., Sarkar, A., Molla, K. A., Chakraborty, K., Ray, S. and Sarkar, R. K.: Genetic dissection of component traits for salinity tolerance at reproductive stage in rice. Plant Molecular Biology Reporter. 2020.

13) Mohammadi, R., Mendioro, M. S., Diaz, G. Q., Gregorio, G. B. and Singh, R. K.: Mapping quantitative trait loci associated with yield and yield components under reproductive stage salinity stress in rice (Oryza sativa L.), Journal of Genetics, Vol. 92, No. 3, pp. 433-443, 2013.
14) Lang, N. T., Phuoc, N. T., Ha, P. T. T. and Buu, B. C.: Identifying QTLs associated and marker-assisted selection for salinity tolerance at the seedling, vegetative and reproductive stages in rice (Oryza Sativa L.), Journal of Agriculture Environment \& Biotechnology, vol. 2, no. 6, pp. 2927-2935, 2017.

15) Sabouri, H. and Biabani A.: Toward the mapping of agronomic characterization of a rice genetic map QTL anaysliss under saline condition, Biotechnology, Vol. 8, No. 1, pp. 144-149, 2009.

16) Yeo, A. R., Yeo, M. E., Flowers, S. A. and Flowers, T. J.: Screening of rice (Oryza sativa L.) genotypes for physiological characters contributing to salinity resistance, and their relationship to overall performance, Theoretical and Applied Genetics, Vol. 79, No. 3, pp. 377-384, 1990.

17) Makihara, D., Tsuda, M., Morita, M., Hirai, Y. and Kuroda, T.: Effect of salinity on the growth and development on rice (Oryza sativa L.) varieties, Japanese Journal of Tropical Agriculture, Vol. 43, No. 4, pp. 285-294, 1999.

18) Bimpong, I. K., Manneh, B., Diop, B., Ghislain, K., Sow, A., Amoah, N. K. A., Gregorio, G., Singh, R. K., Ortiz, R. and Wopereis, M.: New quantitative trait loci for enhancing adaptation to salinity in rice from Hasawi, a Saudi landrace into three African cultivars at the reproductive stage. Euphytica, Vol. 200, No. 1, pp. 45-60, 2014.

19) Chai, L., Zhang, J., Pan, X., Zhang, F., Zheng, T., Zhao, X., Wang, W., Ali, J., Xu, J. and Li, Z.: Advanced backcross QTL analysis for the whole plant growth duration salt tolerance in rice (Oryza sativa L.). Journal of Integrative Agriculture, Vol. 13, No. 8, pp. 1609-1620, 2014.

20) Singh, R. K., Gregorio, G. B. and Jain, R. K.: QTL mapping for salinity tolerance in rice, Physiology and Molecular Biology of Plants, Vol. 13, No. 2, pp. 87-99, 2007.

21) Khatun, S., Rizzo, C. A. and Flowers, T. J.: Genotypic variation in the effect of salinity on fertility in rice, Plant and Soil, Vol. 173, No. 2, pp. 239-250, 1995.

22) Kumar, J., Gupta, D. S., Gupta, S., Dubey, S., Gupta, P., Kumar, S.: Quantitative trait loci from identification to exploitation for crop improvement, Plant Cell Reports, Vol. 36, No. 8, pp. 1187-1213, 2017.

23) Ammar, M. H. M., Pandit, A., Singh, R. K., Sameena, S., Chauhan, M. S., Singh, A. K., Sharma, P. C., Gaikwad, K., Sharma T. R., Mohapatra, T. and Singh, N. K.: Mapping of QTLs controlling $\mathrm{Na}^{+}, \mathrm{K}^{+}$and $\mathrm{Cl}^{-}$ion concentrations in salt tolerant indica rice variety CSR27. Journal of Plant Biochemistry and Biotechnology, Vol. 18, No. 2, pp. 139150, 2009.

24) Pandit, A., Rai, V., Bal, S., Sinha, S., Kumar, V., Chauhan, M., Gautam, R. K., Singh, R., Sharma, P. C., Singh, A. K., Gaikwad, K., Sharma, T. R., Mohapatra, T., Singh, N. K.:
Combining QTL mapping and transcriptome profiling of bulked RILs for identification of functional polymorphism for salt tolerance genes in rice (Oryza sativa L.), Molecular Genetics and Genomics, Vol. 284, No. 2, pp. 121-136, 2010.

25) Fayed, A. M. and Farid, M. A.: Mapping of quantitative trait loci (QTL) for $\mathrm{Na}^{+}$and $\mathrm{K}^{+}$uptake controlling rice salt tolerance (Oryza sativa L.). International Journal of Current Microbiology and Applied Sciences, Vol. 6, No. 1, pp. 462-471, 2014.

26) Liu, C., Chen, K., Zhao, X., Wang, X., Shen, C., Zhu, Y., Dai, M., Qiu, X., Yang, R., Xing, D., Pang, Y. and Xu, J.: Identification of genes for salt tolerance and yield-related traits in rice plants grown hydroponically and under saline field conditions by genome-wide association study, Rice, Vol. 12, No. 1, 2019.

27) Jaiswal, S., Gautam, R. K., Singh, R. K., Krishnamurthy, S. L., Ali, S., Sakthivel, K., Iquebal, M. A., Rai, A. and Kumar, D.: Harmonizing technological advances in phenomics and genomics for enhanced salt tolerance in rice from a practical perspective, Rice, Vol. 12, No. 1, pp. 1-19, 2019.

(Received: January 29, 2021) 